\title{
EXPERIMENTS ON THE EMISSION AND ABSORPTION OF RADIATION BY METALLIC SILVER
}

\author{
By F. L. Mohler
}

\section{ABSTRACT}

The emission spectrum of silver bombarded by electrons is characterized by a high intensity from the visible to $3,600 \mathrm{~A}$, with a decrease to a very low value beyond $3,200 \mathrm{~A}$.

The spectrum emitted by silver bombarded by 100-volt electrons in high vacuum is similar to the emission of a silver probe surface at a low positive potential in a cæsium discharge.

Probe emission spectra at different temperatures have been compared and a small effect found which may or may not be a pure temperature effect. The slope between $3,600 \mathrm{~A}$ and 3,200 A becomes slightly less with a shift toward longer wave length with increasing temperature.

The absorption of a silvered quartz plate has been measured at temperatures between $20^{\circ}$ and $490^{\circ} \mathrm{K}$. There is a large increase in absorption with increasing temperature limited to the range 3,350 to $2,950 \mathrm{~A}$ with a maximum effect at $3,100 \mathrm{~A}$. The effect is a decrease in slope of the violet edge of the selective transmission band with increasing temperature.

The results are contrary to a theory proposed by Boeckner and the author. The observed change in emission is less and in absorption much greater than the predicted effect.

\section{CONTENTS}

I. Introduction

I. Radiation from silver bombarded by cathode rays in high vacuum - $\quad 359$

III. Effect of temperature on silver emission

IV. Effect of temperature on absorption

V. Discussion

\section{INTRODUCTION}

In two recent papers ${ }^{1}$ Boeckner and the author describe the continuous spectra emitted by metal surfaces bombarded by low-speed electrons. For most metals the radiation is a nearly equal energy spectrum of comparable intensity, but silver and copper show relatively intense characteristic emission bands. The silver band begins near 3,200 A, rises to a maximum near 3,600 A, and drops gradually with increasing wave length. The copper emission increases in the red. The abrupt increase comes at the points where the absorption and reflection of the metals suddenly increase. Thus, internal reflection and absorption tend to diminish the observed emission, and in paper No. 371 we have applied a correction for internal reflection by dividing observed intensities by $1-R$, where $R$ is the reflection coefficient for normal incidence. The use of this reflection correction may be open to question, but for want of anything better I have

1 Mohler and Boeckner, B. S. Jour. Research, vol. 6 (RP297), p. 673, 1931; and vol. 7 (R P371), p. 751, 1931. The second paper will subsequently be referred to as paper No. 371 . 
continued to use it. Figure 1 is taken from paper No. 371, and it shows the emission intensity distribution and the absorption curves for silver and copper. The edge of the silver band was shown to be exactly the form of the Fermi Sommerfeld distribution in energy for conduction electrons with an assumed temperature of $370^{\circ} \mathrm{C}$., which is a reasonable value for the probe temperature under operating conditions.

This agreement" suggested "the theory that the emission process involves the ionization of a sharply defined underlying level with the consequent radiation transition of one of the conduction electrons into the ionized shell. This is identical with the process of characteristic X-ray emission, and Houston ${ }^{2}$ has shown that the width of soft $\mathrm{X}$-ray lines ( $B e K \alpha$ in particular) corresponds closely to the predicted range of energy of the conduction electrons. Nevertheless, the theory as applied to the visible and near ultra-violet emission of silver is in certain aspects radical and extreme. The Fermi Sommerfeld distribution of energy is derived from an approximation which takes no

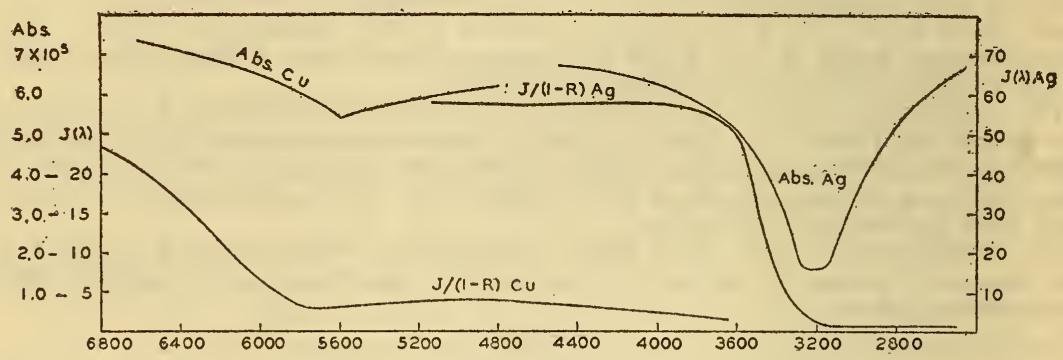

FIGURE 1.-Intensity distribution of silver and copper radiation corrected for internal reflection, from paper No. $\mathbf{3 7 1}$

Absorption coefficients of copper and silver in $\mathrm{cm}^{-1}$.

account of atomic fields in a metal, and Houston's analysis of X-ray line shapes shows that the distribution is better represented by a theory of Bloch ${ }^{3}$ which treats the electrons as moving in atomic fields which are greatly perturbed by close packing of the atoms. On this view an underlying level, 3.56 volts below the top of the continuum of conduction electrons, can not be sharply defined as was assumed to explain the silver emission.

In paper No. 371 it was suggested that the branch of the absorption curve extending toward shorter wave lengths came from absorption from the underlying level. If the level is appreciably broadened, then the violet edge of the emission band and the red edge of the absorption band will overlap, so this interpretation is not consistent with Bloch's theory.

The subject seemed to call for critical examination of the earlier work and further experiments to look for a temperature variation of the emission and absorption spectra of metallic silver. This paper reports three entirely separate experiments carried out for this purpose.

Houston, Phys. Rev., vol. 38, p. 1797, 1931

F. Bloch, Phys. Zeits, vol. 32, p. 881, 1931. 


\section{RADIATION FROM SILVER BOMBARDED BY CATHODE RAYS IN HIGH VACUUM}

Measurements of the silver emission have been made by observing the radiation emitted by a small probe surface at a positive potential in a cæsium vapor discharge. The cæsium discharge has the advantage that the radiation intensity of the vapor is very small, but the probe surface becomes cæsiated, and it may be questioned whether the radiation from the probe is characteristic of pure silver.

The technique of studying radiation of metals bombarded by electrons in high vacuum is being developed by L. S. Taylor, and will be described in detail later. To study silver radiation, I have used an oxide-coated platinum strip cathode about $1 \mathrm{~mm}$ from the anode,

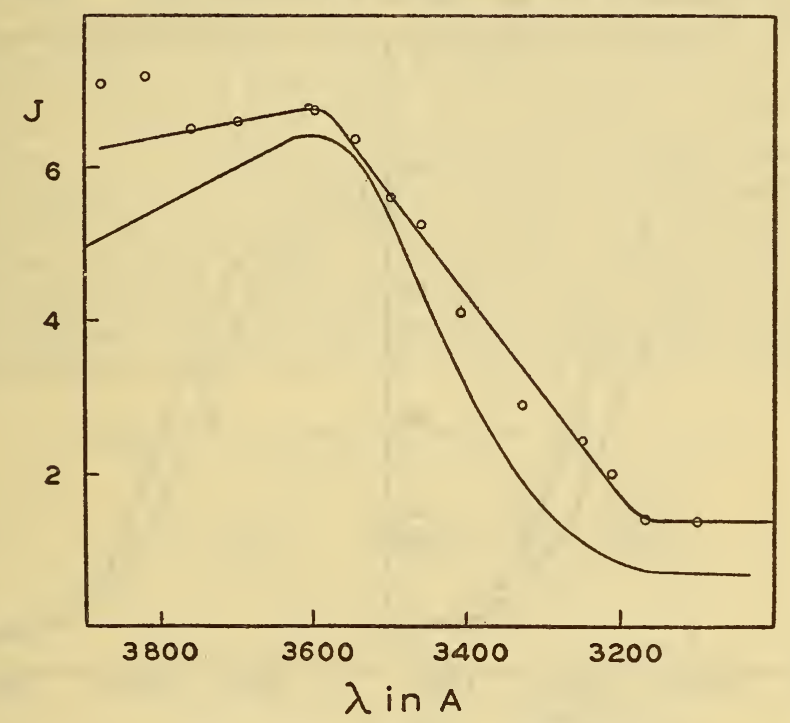

FIGURE 2.-Emission of silver

Uppericurve with 100 -volt electrons in vacuum; lower curve with 7-volt electrons in a cæsium discharge

which was a disk of silver $1 \mathrm{~cm}$ in diameter. The silver surface was viewed almost tangentially and the spectrum of the emitted radiation compared with a tungsten strip lamp. It was impossible to avoid discoloration of the silver by material distilled or sputtered from the cathode, and the silver radiation is doubtless more or less masked by impurities. Figure 2 shows the intensity distribution in vacuum at 100 volts and for comparison the silver radiation observed in a cæsium discharge at 7 volts. The vacuum intensity measurement is taken from a four and one-half hour exposure with a current of $16 \mathrm{ma}$. With this current the anode is maintained at a barely visible red heat, certainly less than $600^{\circ} \mathrm{C}$. and probably above $550^{\circ} \mathrm{C}$. This datum will be referred to later. Other spectrograms gave curves qualitatively like the one shown, though the shapes were never identical and the surface was always conspicuously contaminated. The important fact is that the short wave length edge of the emission band falls in the same wave length range $(3,200$ to $3,600 \mathrm{~A})$ in vacuum as in cresium 
vapor. In paper No. 371 we include inaccurate measurements of silver radiation from a probe in a helium discharge which support the conclusion that cæsium does not modify the silver radiation.

\section{EFFECT OF TEMPERATURE ON SILVER EMISSION}

The radiation from a probe surface in a cæsium discharge has been used in these experiments with the arrangement of electrodes shown in paper No. 371 (fig. 1) except that the probe electrode was much heavier. A rod $1 \mathrm{~cm}$ in diameter was turned down to $3 \mathrm{~mm}$ at the end and all except this end surface insulated with glass. The rod was supported in a side tube of nearly the same diameter and the temperature of the side tube was controlled by a separate electric heater and measured by an external thermometer. The probe was

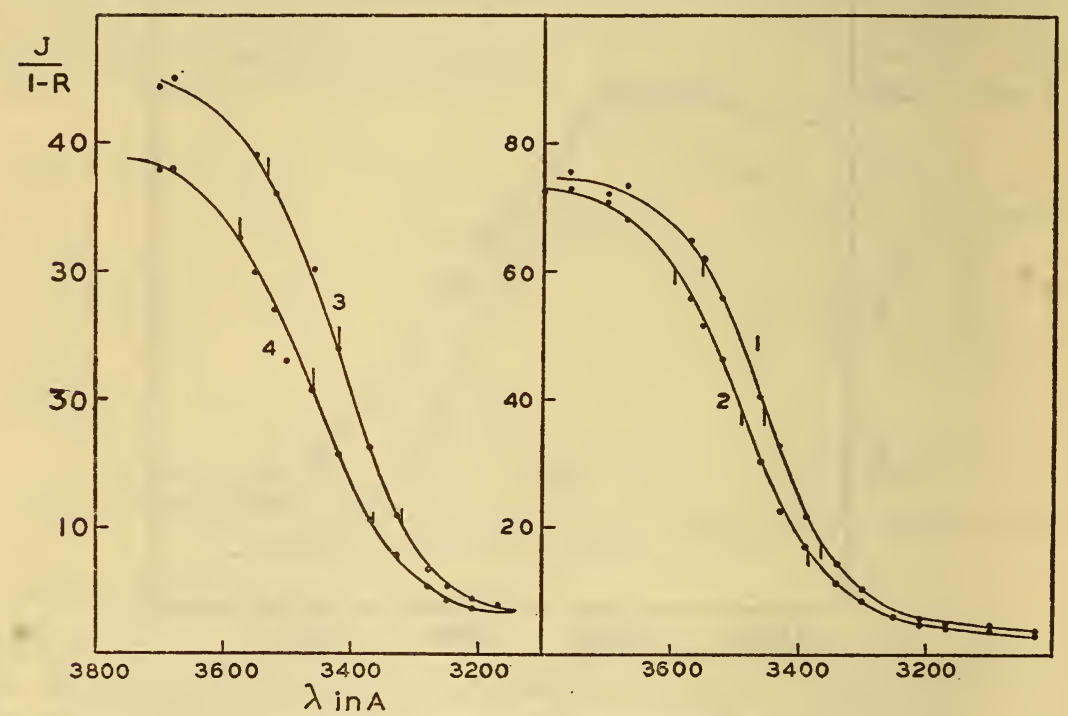

FIgURE 3.-Intensity of silver radiation at different temperatures

1 and 2 from successive exposures at $200^{\circ}$ and $390^{\circ}$ C.; 3 and 4 from exposures at $210^{\circ}$ and $400^{\circ} \mathrm{C}$. Points $V_{0}, V_{1}, V_{2}$ as defined in the text are indicated on each curve

designed to secure maximum thermal conductivity and it is probable that the temperature change of the exposed surface was about the same as that measured by the thermometer while the actual temperature was somewhat higher (estimated at $50^{\circ}$ higher in Table 1) because of heating by electron bombardment.

The procedure was to compare exposures at a low temperature and at $200^{\circ}$ to $300^{\circ}$ above this temperature with conditions otherwise kept as constant as possible. However, there was evidence of some uncontrolled factor, probably surface contamination of the silver which caused the intensity to vary. Positive ion bombardment of the probe reduced the variation, but in general at higher temperatures the intensity and the intensity ratio $J(3,700) / J(3,100)$ were lower. The temperature variation of the optical constants of silver described in the following section does not explain the difference.

Figure 3 shows two pairs of curves of $J(\lambda) / 1-R$ as a function of $\lambda$. The temperature change was in each case about $200^{\circ} \mathrm{C}$. Four such 
pairs of curves and the two curves of Figure 2 have been analyzed in accord with the theory given in paper No. 371. $J=(J(\lambda)-J(3,100))$ / $(1-R)$ plotted on a voltage scale (the scale is unimportant for this small range) is approximately of the form of a Fermi Sommerfeld distribution of energy ${ }^{4}$ so we can write:

$$
J=c /(\exp x+1) \quad x=e\left(V-V_{0}\right) / k T
$$

$c$ is taken as $J(3,700)-J(3,100), V$ is the coordinate and $V_{0}$ the coordinate of the point where $J=c / 2$. Values $V_{1}$ and $V_{2}$ of $V$ have been determined for the points where $x= \pm 1.5 J=0.182 c$ and $J=$ $0.82 \mathrm{c}$. Then if the underlying assumptions are correct,

$$
T=11,600\left(V_{1}-V_{2}\right) / 3
$$

Table 1 summarizes the results. The estimated probe temperature is given in column 2 while column 3 gives the temperature computed from $V_{1}-V_{2}$. Column 4 gives the mid-point of the curve in Angstroms. The computed temperature does not correspond to the measured temperature. The difference in computed temperatures between two observations of a pair is always less than the temperature change and the computed temperature is, in general, greater than the actual temperature. A shift in wave length of 30 or $40 \mathrm{~A}$ toward the red at the higher temperature is shown in each pair of measurements; but, from the method of measuring and computing curves, comparisons between different sets of observations are of doubtful significance.

\begin{tabular}{|c|c|c|c|}
\hline $\begin{array}{l}\text { Figure and curve } \\
\text { No. }\end{array}$ & $\begin{array}{l}\text { Silver } \\
\text { tempera- } \\
\text { ture }\end{array}$ & $\begin{array}{l}T^{\circ} \mathrm{K} \text {. } \\
\text { from } \\
\text { equation } \\
(2)\end{array}$ & $\begin{array}{l}\text { Wave } \\
\text { length } \\
\text { of mid- } \\
\text { point }\end{array}$ \\
\hline Fig. $3,1$. & ${ }^{\circ} K_{473}$ & 735 & 3,455 \\
\hline \multirow[t]{3}{*}{ Fig. 3, 2-- } & 663 & 810 & 3,490 \\
\hline & $\left\{\begin{array}{l}473 \\
673\end{array}\right.$ & $\begin{array}{l}735 \\
810\end{array}$ & $\begin{array}{l}3,480 \\
3,510\end{array}$ \\
\hline & $\left\{\begin{array}{l}493 \\
793\end{array}\right.$ & $\begin{array}{l}810 \\
890\end{array}$ & $\begin{array}{l}3,475 \\
3,505\end{array}$ \\
\hline $\begin{array}{l}\text { Fig. } 3,3 \\
\text { Fig. } 3,4, \ldots \\
\text { Fig. } 2,1 \\
\text { Fig. } 2,2, \ldots \\
\end{array}$ & $\begin{array}{r}483 \\
673 \\
600 ? ? \\
820\end{array}$ & $\begin{array}{l}850 \\
850 \\
640 \\
890\end{array}$ & $\begin{array}{l}3,420 \\
3,460 \\
3,465 \\
3,470\end{array}$ \\
\hline
\end{tabular}

$T_{A B L E}$ 1. - The change in emission with temperature

\section{EFFECT OF TEMPERATURE ON ABSORPTION}

There have been several papers on the temperature variations in the optical properties of silver; all of them qualitative observations showing a shift in the reflection and absorption minimum toward longer wave length and an increase in absorption with increasing temperature. ${ }^{5}$ The following measurements of absorption were made

Tarrow, Phys. Rev. Supplement (Review of Modern Physics), vol. 1, p. 90, 1929.

De p. 247,1925 .

Rayleigh, The Ultra-violet Transmission Band of Silver as Affected by Temperature, Proc. Roy. Soc., vol. 128, p. 131, 1930.

McLennan, Smith, and Wilhelm, The Effect of Low Temperature on the Ultra-violet Transmission Band of Silver, Phil. Mag. vol. 12, p. 833, 1931. 
using the usual methods of densitometry to compute the absorption from spectrograms of the transmitted light.

The source of light was a hydrogen discharge tube photographed end on with a Hilger $E_{2}$ quartz spectrograph. Two kinds of silver films were used; silver chemically deposited on a quartz plate, and silver evaporated in high vacuum on to the walls of a quartz bulb. The second method was tried in the hope that higher temperatures could be used without injuring the silver when it was in a vacuum, but no significant improvement or difference was seen. Both types of deposit rapidly deteriorate above $220^{\circ} \mathrm{C}$. Measurements above room temperature were obtained by placing the plate or bulb in a small tube furnace and measuring the change in transmission with changing temperature. For the low temperature measurements liquid air or hydrogen was contained in a transparent quartz Dewar flask and the silvered disk immersed in the liquid. There was a large loss of light by scattering in passing through the flask and boiling liquid and measurements were made of the intensity change with and without the disk in the path of light.

Liquid hydrogen rapidly becomes clouded with solid air particles unless some precautions are taken. The hydrogen was forced by compressed hydrogen from the container into the quartz flask through a filter. With the mouth of the quartz flask stopped with cotton to reduce air circulation, the liquid remained clear for many minutes.

In the usual notation the transmission of a metal film of thickness $x$ is expressed by the equation

$$
\begin{aligned}
& J=J_{0} \exp (-4 \pi n k x / \lambda) \\
& \log J_{0}-\log J=(4 \pi n k x / \lambda) \log e=a
\end{aligned}
$$

Here $J$ is the transmitted intensity corrected for loss of light by reflection. As the reflection is not known at the temperatures used we have omitted the correction, but the error introduced is small in the range where the temperature change is large. Between 3,050 and 3,250 it is less than 0.04 in $\log J-\log J_{0}$. Thus the observed change, 0.78 for the extreme range of temperature must measure predominantly a change in $n k$ with temperature.

Several silver films, both evaporated and chemically deposited, were studied between $30^{\circ} \mathrm{C}$. and $145^{\circ} \mathrm{C}$. and the change in $a$ was found to be nearly proprotional to $a$. Thus at $3,100 \mathrm{~A}$ the values of $a$ were $0.96,1.67$, and 2.13 and the values of the change in $a$, divided by $a$ at $30^{\circ}$, were $0.161,0.165$, and 0.160 . This is consistent with the conclusion that the reflection correction is negligible.

Figure 4 gives measurements on a single sample at room temperature, $220^{\circ} \mathrm{C}$. and $-253^{\circ} \mathrm{C}$. Deviations of measurements in liquid hydrogen from the mean curve for wave lengths greater than 3,400 $\mathrm{A}$ and less than 2,900 A are probably accidental. All other measurements indicate that there is no temperature effect outside of the range 2,900 to $3,350 \mathrm{~A}$. Within this range the effect is large, giving a sixfold change in intensity at the maximum. The change is nearly proportional to the temperature difference. Thus between -253 and $30^{\circ} \mathrm{C}$. the maximum change is 0.00178 per degree and between $40^{\circ} \mathrm{C}$. and $220^{\circ} \mathrm{C}$. it is 0.00156 per degree. A film of different thickness gave 0.00139 per degree between $-180^{\circ} \mathrm{C}$. and $145^{\circ} \mathrm{C}$. which corresponds to 0.00152 per degree for equal thickness. 
As the change is nearly proportional to the temperature one can apply a small correction to the curve at $-253^{\circ} \mathrm{C}$. to derive the form of the absorption curve at absolute zero, but the difference (0.04 at the maximum) is scarcely appreciable.

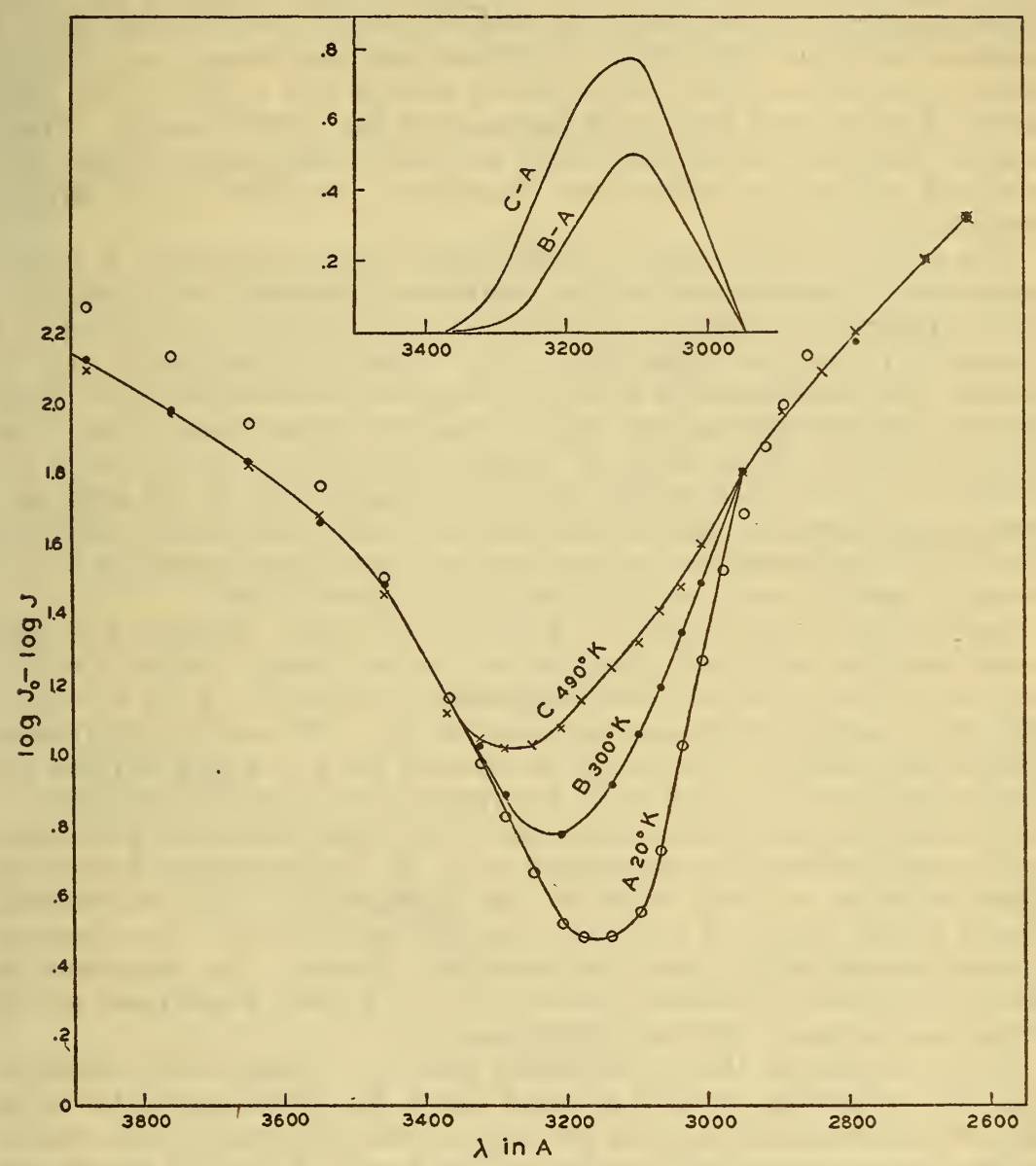

FIgURE 4.-Absorption of a silver film at liquid hydrogen temperature, room temperature, and $220^{\circ} \mathrm{C}$.

Inset, the change in absorption, the difference between the lower curve and the other curves.

In published work interest has centered on the shift in the minimum of the absorption curve. The curves of Figure 4 give the following values for the minimum:

$$
20^{\circ} \mathrm{K} ., 3,155 \mathrm{~A} ; 300^{\circ} \mathrm{K} ., 3,220 \mathrm{~A} ; 490^{\circ} \mathrm{K} ., 3,275 \mathrm{~A}
$$

In Figure 4 we include a plot of the temperature change as a function of wave length. Other measurements gave similar curves except that the two curves were not coincident at the short wave length side so this feature of the curves may be accidental. 


\section{DISCUSSION}

The results do not support the theory proposed in paper No. 371 that the selective emission results from the transition of electrons from a Fermi distribution into a sharply defined underlying level. Measurements of the change in emission with temperature show a decrease in slope of the edge of the band with increasing temperature which is much less than the predicted change and a shift of the edge toward longer wave lengths of about $30 \mathrm{~A}$ for a $200^{\circ}$ change. There is some doubt as to whether these are pure temperature effects or a result of surface contamination. In general, the slope is less than is predicted by theory.

The study of the change in absorption with temperature is inadequate and a measurement of the variations of $n$ and $k$ with temperature is desirable. Assuming, however, that the observed effect is a measure of the true absorption, the following conclusions can be drawn. The absorption of a sharp energy level at absolute zero would give a vertical edge and a nearly constant absorption beyond the edge. A Fermi distribution at higher temperature would cause the absorption to increase on the long wave length side of the edge and decrease on the other side by an equal amount. This is not what was observed, but it is interesting to note that a modification of this theory accounts qualitatively for the absorption observations.

Assume that the underlying level is not sharply defined, but contains electrons uniformly distributed over an energy range of a volt or more. Then the absorption at absolute zero will not have a vertical edge, but a nearly uniform slope, as observed. The result of increasing temperature will be to round off the foot of the curve and increase the absorption near the foot with no appreciable decrease anywhere if the underlying level is wide enough. The change will be a maximum at the point where the absorption at $0^{\circ} \mathrm{K}$. begins and will drop off symmetrically on both sides of the maximum. This corresponds closely to the observed variation, but the magnitude of the observed change is much larger than the theoretical change. The equations for the temperature variation of absorption by a finite band need not be given here as their applicability is doubtful.

It was shown in the introduction that it is reasonable to assume that the underlying level is a broad band, but if this is so the violet edge of the emission and the red edge of the absorption will overlap by an amount equal to the width of the band. Thus the simple pictures of the absorption and emission processes that I have used are clearly inadequate. A theory such as one of Kronig ${ }^{6}$ which accounts for absorption by transitions of electrons from a continuum of normal states, but with sharp selection principles governing the transitions can remove the apparent contradictions involved in pure energy considerations.

I am indebted to F. G. Brickwedde and J. W. Cook of the low temperature laboratory for their cooperation in the low temperature experiments and to C. Boeckner for many helpful suggestions.

Washington, January 4, 1932.

${ }^{6}$ Kronig, Proc. Roy. Soc., vol. 124, p. 409, 1929. 